\title{
Teachers' Views towards Changes in Curriculum and the Use of Real-Time Big Data in Statistics Education
}

\author{
Oziah Othman, Zanaton H. Iksan*, Ruhizan Mohamad Yasin \\ Universiti Kebangsaan Malaysia, Bangi, Selangor, Malaysia \\ Email: *zanaton.iksan@ukm.edu.my
}

How to cite this paper: Othman, O., Iksan, Z. H., \& Yasin, R. M. (2021). Teachers' Views towards Changes in Curriculum and the Use of Real-Time Big Data in Statistics Education. Creative Education, 12, 2424-2440. https://doi.org/10.4236/ce.2021.1210182

Received: September 24, 2021

Accepted: October 26, 2021

Published: October 29, 2021

Copyright ( 2021 by author(s) and Scientific Research Publishing Inc. This work is licensed under the Creative Commons Attribution International License (CC BY 4.0).

http://creativecommons.org/licenses/by/4.0/

\section{(c) (i) Open Access}

\begin{abstract}
Currently, the demands on big data applications in varieties of fields are rising. The existence of big data has to be benefitted so that the information can be analysed creatively for the public's interest. To ensure that the existence of big data can be beneficial to all parties, statistical skills and big data have to be integrated together with the changes in statistics education. This study is to explore the teachers' views towards the changes in statistics education in Malaysia, as well as their views on the use of real-time big data in statistics education for Secondary Four students. This qualitative research involves two methods of data gathering, which are statistics education's documents analysis, and partially structured interview involving ten teachers. Theme analysis is used to analyse the data. The outcome shows that according to the teachers, changes in statistics education are getting broader and suited with the needs of the generation of the era of big data. However, the aims of statistics education are difficult to achieve due to several obstacles that can be categorized into four main factors: 1) approach and arrangement of the contents of statistics education's curriculum; 2) the need of high-level statistical skill; 3) teachers' abilities in teaching statistics; and 4) lack of supporting documents and tools, as an aid and guidance, for teachers teaching statistics. Supporting documents and tools are needed to help teachers in increasing their knowledge and pedagogical skill in teaching statistics, considering the rapid growth of the statistics field in the era of big data. The teachers are with a positive view that, the usage of real-time big data in Secondary Four students. The implication of this study is that the statistical education curriculum needs to be given attention and developed in line with the needs of students to prepare themselves in facing the big data phenomenon which will continue to grow in the future.
\end{abstract}




\section{Keywords}

Teachers' Views, Changes in Curriculum, Statistics Education, Real-Time Big Data

\section{Introduction}

The word statistics derives from a modern Latin term that brings a meaning "council of state". In day-to-day life, statistics can be found easily from everywhere (Rahayu \& Wijaya, 2018). In this current era of big data, almost every area of human life is using statistics as an essential skill to help solve problems, especially problems involving data. In fact, Taylor-Sakyi (2016) stated that economy industries in the $21^{\text {st }}$ century are relying heavily on data, hence involving statistical skill. By applying statistics, it allows data to be interpreted more easily and in turn making the presented data to be more meaningful (Meylasari et al., 2021).

Data field is continuously evolving, and it is becoming more and more challenging for individuals as well as organizations to interpret. Moreover, almost every current public issue is relying on the use of data (Bailey et al., 2020) that will be presented to the public through a variety of mediums, notably electronics media and then it will be down to the individuals to interpret them. Inaccuracies in interpreting data can potentially affect any planning or decisions that have been made (Baig et al., 2020). Hence, statistical skill is essential to improve the public's capability in applying data. Unfortunately, thinking statistically which plays an important role in different aspects of life is still absent in most parties (Bailey et al., 2020). Plus, majority of the society who are not familiar with statistics tend to think that statistics is only involving moderate numerical data and the technic to process this data (Lee, 2015). The truth is, this is just a small part of statistics.

In the education field, the level of achievement in international level assessment Trends in International Mathematics and Science Study (TIMSS) among Malaysia students is the second lowest compared to the overall average scores, especially in Data and Probabilities. The difference is quite significant compared to the average score for country such as Singapore, which in the first place with an average score of 620. There was an improvement, particularly in Data and Probabilities, which is 457 (2019) compared to 451 (2015), but this figure is still far behind. In Data and Probabilities, there are more data diagrams such as bar graphs, line graphs, and pie charts included in the questions/problems. This shows that students aren't familiar enough with data distributions in statistics which further causes them not able to link between the data contained in the diagrams. The low scores in Data and Probabilities describe the situation among students in Malaysia that are not firm enough in the concepts in statistics. Table 1 shows the achievement trends among Malaysia students by each Mathematics domains in TIMSS. 
Table 1. Malaysia achievement trends by each Mathematics domains.

\begin{tabular}{ccccc}
\hline Mathematics Domains & $\mathbf{2 0 0 7}$ & $\mathbf{2 0 1 1}$ & $\mathbf{2 0 1 5}$ & $\mathbf{2 0 1 9}$ \\
\hline Numbers & 494 & 451 & 472 & 458 \\
Algebra & 455 & 430 & 467 & 456 \\
Geometry & 474 & 432 & 455 & 466 \\
Data \& Probabilities & 459 & 429 & 451 & 457 \\
\hline
\end{tabular}

Source: Ministry of Education Malaysia (2020).

It is important for students to have statistical knowledge, skill and ability in order for them to understand data so that it can be applied in their studies as well as in their daily life (Lukman \& Wahyudin, 2020). Based on these problems, there should be a specific study related to the changes in the statistics curriculum that occur in Malaysia education system. This is important because in the current era of big data, the field of statistics is growing so fast that it requires all communities to master statistical skills. Changes in the statistical education curriculum need to be developed based on the needs of the present generation so that they can apply the acquired knowledge effectively in their lives. Therefore, this research is to explore teachers' views on the changes in statistics education's curriculum and the use of real-time big data in statistics education for Secondary Four students. This study helps provide information and guidance especially to curriculum developers in preparing curriculum in statistics education so that further improvements can be implemented aimed to help equipping students with the statistical skills needed in facing the challenges of the big data era.

\section{Statistics Education for the Generation of Big Data}

A proactive measure is needed to improve statistics education so to align with the need of current generation, and this is important to nurture students with the ability to understand and to exploit big data. Statistics education has long been included in education system in most countries. Furthermore, in most countries' curriculum, statistics is a topic widely covered in different levels ranging from primary school to secondary school. This shows that statistics has an important significant role in daily life (Meylasari et al., 2021). However, the world changes simultaneously with the advancement of technology that causes big data dumping phenomenon.

Big data refers to big data dumping, be it structured or non-structured, and when it is organized it is capable to produce results that are beneficial when it comes to decisions making (Storey \& Song, 2017). The existence of big data represents a change in paradigm on how to benefit and analyse information creatively for the public interest (González et al., 2020). The emergence of huge data dumping might create challenges in the statistics education (Johnson, 2019), though the usage of big data in statistics education should be introduced to students (Baig et al., 2020). Big data will continue to evolve and it has to be benefitted for the public. Hence, statistics education curriculum has to be 
alligned with the need of the generation of the era of big data so, as well as the society.

As a guide for the curriculum developers, the researcher is making this literature research on statistics education curriculum especially that in involving countries with high achievements in international-level assessment, such as TIMSS, particularly on Data and Probabilities. Literally, the researcher have concluded that statistics education curriculum in the age of big data has to emphasize on two main points below:

1) Focusing on the aims of statistical skill development;

2) Curriculum arrangement following the sequence of statistics, probabilities and calculations.

\subsection{Focusing on the Development of Statistical Skill}

Research in statistics field has supported the need of nurturing society with decent statistical skill as important as much as reading and calculation skills (Ramadhani et al., 2018; Marriott, 2014). At the international stage, statistics skill has emerged as a skill with high importance for every age, ranging from children in schools to adults. This is since, statistics skills are required in almost every aspect of human activities (Bailey et al., 2020; Ramadhani et al., 2018). Further literature research has proven that statistics skill positively impacting the efficiency and the quality of numerous fields such as medical (Lee, 2015; Cox \& Efron, 2017), management (Storey \& Song, 2017), agriculture (Toledo et al., 2018), education (Baig et al., 2020; Ramadhani et al., 2018; Zhang \& Stephens, 2016) and others.

American Statistical Association in their educational document Guidelines for Assessment and Instruction in Statistics Education (GAISE) has stated that the main aim in statistics education is to nurture students with statistics education background, and with the ability to think statistically (Garfield et al., 2015). The suggestion by GAISE have shown that in the era of big data, statistics education should aim to focus on nurturing students that have the ability to think statistically when facing different types of data. Hence, statistics education's curriculum development should emphasize on the process of statistical thinking (Cummiskey et al., 2020; Le, 2017; Garfield et al., 2015). There are four main processes in statistical thinking that are interconnected to one another, which are elaboration of data, re-arrangement and compression of data (data handling), representations of data, and analysis and interpretation of data (Meylasari et al., 2021; Masjudin et al., 2020), as per Figure 1.

The need to stress on the importance of statistical thinking in statistics education through teaching and learning strategies (Alston-Knox et al., 2019; Ramadhani et al., 2018; Le, 2017) is done with the aim to change the pedagogical approach and the delivery of contents in statistics field. It has to be suited with the current needs so that it is able to equip the students with the ability to apply this statistics knowledge in their daily life. A literature on the comparisons between 


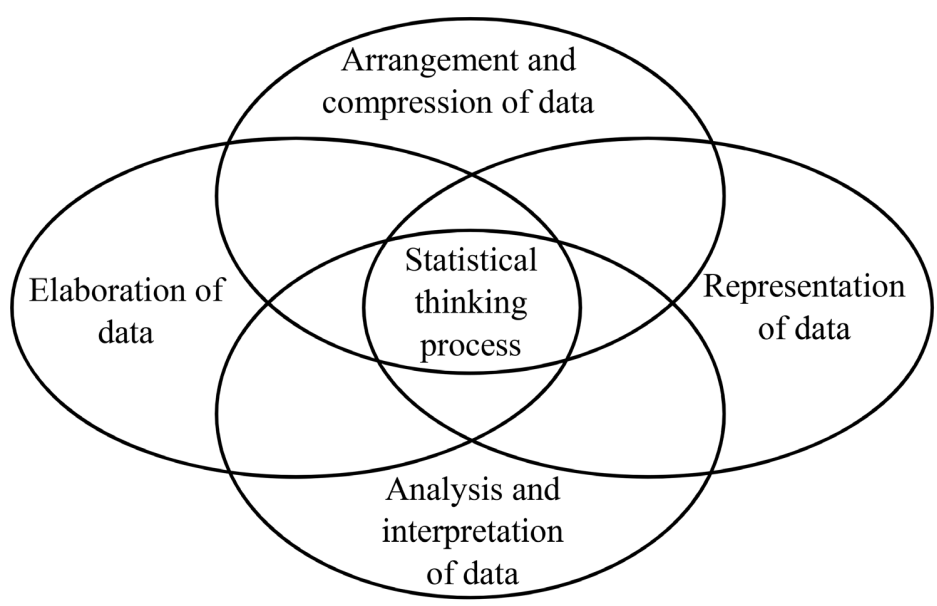

Figure 1. Statistical thinking process.

statistics education curriculum in Singapore and Malaysia shows that, statistics education in Singapore for Grade 10 students (Secondary Four) has lined-up a clear process of statistical thinking compared to the curriculum arrangements in Malaysia. Some of the processes involved in Singapore's statistics curriculum are gathering, classification of statistical data, reading, interpreting, and deriving conclusions from schedules and graphics, representations through constructing and the usage of bar charts, pie charts, pictograms, dot plots and stem-and-leaf plots (Ministry of Education Singapore, 2019). Unlike in Malaysia, statistics education for Secondary Four students is focusing on Dispersion and Measures of Dispersion for Ungrouped Data which covers interpretation and determination of range value, range values between quartiles, variances, and standard deviations (Ministry of Education Malaysia, 2018).

As for Australia and China, both are set on clear objective for statistics and probabilities topics which are referring to the importance of statistical methods, expanding the idea of statistical analysis, and embracing the statistical thinking phenomenon (Australian Curriculum, 2015; Wang et al., 2017). On the opposite, statistics education curriculum in Malaysia, statistical thinking is not clearly highlighted as a skill that needs to be mastered. The use of a more appropriate and accurate term can help the users of the curriculum documents, which are the teachers, to be clear on the main objective of teaching and learning of statistics. Hence, the teachers will be more aware and attentive on the need to deliver the teaching and learning that are focusing on the development of statistical thinking in the students aligning with the recommendations that have been implemented in statistics education on the global scale.

\subsection{Approach of Priority Sequencing from Statistics, Probabilities and to Calculation}

Statistics curriculum in China should be used as a reference. The approach in Mathematics education in China has attracted interests not just from education communities, but from other parties worldwide as well (Wang et al., 2017). Ma- 
thematics Curriculum Standards for Full-time Compulsory Education (MCSFCE) that is being implemented in China is also focusing highly on statistics and probabilities. Through MCSFCE, Statistics and Probabilities is stated as Mathematical literation that is needed for every member of a modern society. Hence, the changes in delivery approach is done by delivering the statistics knowledge through priority sequencing of statistics, probabilities, and calculation methods (Wang et al., 2017). The arrangements of statistics curriculum in Singapore are also based on the same approach which is through priority sequencing from statistics to calculation. As an example, in Data Handling and Analysis topic which is taught to Grade 8 students, the sequence starts with analysis and interpretation of dot diagrams, histograms, and stem-and-leaf diagrams. Min, mod, and median are then introduced, before the students are being brought to measures of central tendency for a set of data, min. Next, further learning on the purpose and the uses of min, mod, and median. Then it concludes with the calculation technics involved to be taught to the students.

It is totally different to the sequencing currently being used in statistics curriculum in Malaysia, which started with calculation technics then only to the concept of statistics. As an example, in Measures of Central Tendencies topic, for Secondary Two (Gred 8) students, the sequencing starts with calculation to determine min, mod and median for a certain set of non-cumulative data. In Secondary Four (Gred 10), for students to learn on scattering measurements, the learning started with determining the ranges of quartile, calculations using formulas for variances and standard deviation (Ministry of Education Malaysia, 2020). At the end of the topic, then only the students will be introduced with elaboration of the pros and cons of every scattering measurement to describe a non-cumulative data, as well as determining the effects of changes in a data on a dispersion based on scattering measurements and graphical representations.

This change of arrangements of the curriculum in following the priority sequencing from statistics to calculations, is done so to broaden the students' mindset to not to confined themselves only on numbers that often thought as the essence of statistics. This can help to promote critical thinking at the introductory state of statistics education. This also can help to prevent students from overrelying on memorizing formulas. The concern is that students might be too comfortable with methods of memorizing formulas and uses of standard procedures instead of thinking actively. It might cause an abandonment of a certain basics in statistics concepts (Maheran \& Abdullah, 2017) which further causing students not able to link the learnings with their daily life.

\section{Methodology}

\subsection{Research Design}

This is a qualitative study focusing on statistics education for Secondary Four (Gred 10) students. The research is to explore teachers' views towards the development of statistics education curriculum in Malaysia and to gather views 
from the teachers on the use of real-time big data in statistics education.

\subsection{Research Participants}

The study used purposive sampling technique to identify and later select ten mathematics teachers as research participants from 10 different schools. One of the selection criteria is for the teachers to have an academic background in Mathematics, at least a bachelor's degree. The participants have to have at least 10 years' experience in teaching Secondary Four (Gred 10) statistics, so to obtain the most accurate data, and relevant to the research being held. The size of participants in this study was determined based on the interview findings. Once the researcher found that no new themes were discovered as a result of the interviews, it meant that the findings of the study were saturated. Therefore, the number of participants in the study was sufficient.

\subsection{Research Instruments}

Data is collected through interviews and documents analysis. The documents used in this research consist of materials from statistics education curriculum to obtain related information on the changes and the developments of statistics education. Partially structured interviews are done to explore on teachers' views thoroughly. The questions in the interviews are also to gather teachers' views regarding the necessity of the use of real-time big data in statistics education for Secondary Four (Gred 10) students. The protocols of the interviews are designed based on literatures findings and discussions with two teachers who are not involved as participants, in relation to the aspects that need to be emphasized to gather information from the participants.

\subsection{Data Analysis}

Before the research is conducted, researchers have obtained consents from each participant before the interviews are conducted. The interview sessions are done through online via Google Meet. Every session of the interviews is recorded, and all data obtained from the interviews are transcribed soon after the interview ended. Theme analysis is used to analyse the data. The data was examined and analyzed to identify patterns and similarities within them. Similar sets of data were grouped together and labelled with suitable or appropriate themes. Nvivo 12-plus software is used to arrange the findings according to themes that have been set after the data is obtained. Excerpts of the interviews are coded by different aliases for every teacher. In the meantime, documents analysis involving Malaysia statistics education curriculum documents is done to support the findings gained from the interviews.

\section{Findings and Discussions}

In this part, findings and discussions on the findings are initiated by the study on teachers' views on the changes of statistics education curriculum for Secon- 
dary Four students. Next, the teachers' views on the use of real-time big data in statistics education for Secondary Four students are being recorded and discussed.

\subsection{Teachers' Views on the Changes in Statistics Education Curriculum}

Based on the interviews, there are four main themes related to the teachers' views on changes in statistics education curriculum: 1) the need of statistics education curriculum; 2) the need of high-level statistical skill; 3) teachers' ability in teaching statistics and; 4) the need of supporting documents/tools for statistics education curriculum.

\section{1) The need of statistics education curriculum}

All participants shared the same positive view on the idea of changes in statistics education curriculum for Secondary Four students. They are in the view that there are numerous changes and improvements that are suited to the current generation's needs. Students will be more exposed to new things related to statistical field due to the broader scope of contents. $70 \%$ of the teachers think that the new curriculum is focusing more on analysing and interpreting data instead of calculations. It aligns to the findings by English and Watson (2015), which stated that there is an increasing awareness on statistics education, and it won't suffice by just focusing on statistical calculations.

Najla is hoping that the difficulties faced by the students in Measures of Dispersion for Ungrouped Data can be overcome by the students. Najla concern is, if this is not achieved, it might cause students losing interest in statistics. As stated by Doluzengin and Kazak (2019), the difficulties faced by students in learning statistics are the obstacles for students to master statistics. $100 \%$ of the students have the same opinion that the impact from this change will be great if students able to achieve the learning objective. Students who managed to master each targeted skills indirectly will be able to realize the application and the importance of statistics in real world.

The other obstacle in statistics education curriculum in Malaysia is the arrangements of the curriculum contents. The arrangements lack emphasis on the development of statistical thinking in students as its main aim, and this is causing further concern that it can lead to teachers to not to focus on this development while teaching the students. According to Maheran and Abdullah (2017), even though statistics have long been in Mathematics curriculum in Malaysia, the emphasis on statistical thinking is still lacking during the process of teaching and learning. This can further cause difficulties in equipping the students with statistical thinking due to the main delivery agent of the curriculum, which is the teachers who are referring to the official curriculum documents provided, are likely not realizing on its importance. Furthermore, findings have shown that teachers are not firm enough in the development of statistical thinking, and not stressing enough on the development of statistical thinking during learning sessions in class. According to Rasyid; 
"Teachers themselves are not entirely clear on the process of statistical thinking. It would be beneficial if there is a guide to teach through statistical thinking process"

(Rasyid)

Based on the documents analysis, within Malaysia statistics education curriculum, statistical skill is not clearly stated as an important skill to be mastered. Instead, the term mathematics skill often used in every aspect including statistics. However, mathematics skill is entirely different to statistical skill, which involved statistical thinking. Appropriate use of term able to let the users of the curriculum documents, especially the teachers, to be clear on the main objective of teaching and learning statistics. Comparing to the situation in Australia and China, the overall objective for statistics and probabilities in the countries' education curriculum is clearly referring to the importance of statistical methods, expanding statistical idea analysis, and through statistical thinking phenomenon (Australian Curriculum, 2015; Wang et al., 2017). Teachers will be more aware on conducting teaching and learning that is focusing more on statistical thinking development in students that is suited with the global recommendations in statistics education.

Another obstacle is the use of fictional data that is still being used in statistics education in Malaysia which causing students not able to see the relevance of statistics implementation in the reality of daily life. Based on the findings, $100 \%$ of the teachers suggested the use of real-time data so to create a learning environment that is close to the reality of students' daily life. The use of real-time data can further ease students in understanding statistics and seeing the importance and its relevance in daily life. According to Yong;

"The use of real-time data is lacking in textbooks. Less focusing on how to guide the students to be able to describe explicitly. The focus is mainly on calculations."

(Yong)

Literature findings showed that in statistical education, the usage of real-time data has become principal that is widely accepted by most statisticians (Chance, 2017). Students will be more motivated by viewing statistics in real-world application since it is more interconnected to their daily life. Ardiansyah et al. (2020) have stated that in order to develop statistical thinking skill in students, a realistic approach is more suited since students able to relate it even better through actual problems. On the other hand, according to Cummiskey et al. (2020), to develop statistical thinking that is the main aim of statistics education, students have to be exposed with the entire process of investigations in statistical thinking which involves interesting real-time situation and data.

\section{2) The need of high-level statistical thinking}

In this study, all teachers have a similar opinion, in which the students are having limited ability in statistical thinking skills. The term "limited" here, ac- 
cording to Shima, students are limited only to the ability in drawing graphs and collecting and arranging data in table forms. However, it is difficult for them to interpret the graphs produced. As for Nura, students do not understand what statistics is, and they only know how to draw graphs without knowing how to use or how to exploit the graphs. These views clearly explain that most students are having low statistical thinking ability. High-level statistical thinking is highly important to ensure students able to apply statistics efficiently in their daily life. Finding by Maheran and Abdullah (2017) is that Secondary Four (Gred 10) students are on Level 1 of statistical thinking process in interpreting and analysing. Level 1 here means students not able to produce relevant statistical interpretation. Masjudin et al. (2020) thinks that students with low statistical thinking ability will not be able to perform data representation due to their lack of understanding in procedures in drawing graphics and diagrams. Students also not able to do complete and thorough comparisons between data (Meylasari et al., 2021). Sue's view below on the overall image of the situation;

"Students not able to link the relevance in deriving ranges, ranges between quartiles, variances, and standard deviations. They are lacking exposures, thus not able to see the idea behind the calculations that they have been doing. They are learning statistics without thinking statistically and not able to link it with their daily life."

Low statistical thinking ability among students might be due to teachers not assessing the students' level of thinking skills during classes. There are documentation or rubric assessments provided to the teachers on this regard. Hence, it is difficult to assess whether the statistics education is achieving its aim of developing statistical thinking. This assessment by the teachers is important. According to Masjudin et al. (2020), by knowing students' ability in thinking statistically, teachers able to identify with contents that are difficult to the students, and obstacles faced by the students. Next, teachers will be able to plan a strategy and preparing aiding tools to enhance statistical thinking in the students.

\section{3) Mathematics teachers' ability in teaching statistics}

Inadequacy in students in statistics also related to the teachers' ability in teaching statistics. From the interviews, even the teachers are hopeful of being given more guidance that can help them in teaching statistics due to the rapid changes in statistics education curriculum in Malaysia, as well as the need of a different teaching approach to be in line with current needs. Fiza has an opinion in which teachers' attitude is also affecting the achievements of the objective in statistics learning. Teachers are being impatient when teaching statistics by providing formulas which in turn causing the concept of linking in statistics education is not delivered. The development of statistical thinking skill in students might be stunted due to this.

Literature findings also have shown that there are doubts on teachers' ability in teaching statistics. In an article by Moore (1988) titled "Should Mathemati- 
cians Teach Statistics" stated that statistics is an education field that is not suited to be taught by teachers with Mathematics qualifications. This argument was based on the fact that statistics is an academic discipline developed from the collection of data. Statistical knowledge is assessed based on its use on researching data and not entirely on mathematics. He believes that high qualifications in mathematics but lacking in experiences in real-life data analysis will cause the teachers not having sufficient knowledge and skills to teach statistics. Gu (2021) also has an opinion that it is unprofessional to allow a mathematician with insufficient experience and knowledge in data field to teach statistics. This is further supported by Adam (2020) who stated that if statistics is being taught by a person with mathematics background, the accurate concept of statistics won't be able to be conveyed fully due to the lack of statistical thinking in those personnel.

Teachers' ability plays an important role in the realization of the important aim through practical learning in classes. However, the reality in Malaysia is, teachers who are teaching mathematics are the teachers who will be teaching statistics as well. This can't be avoided, since the statistics itself is placed under the mathematics subject. Hence, if this role to be continued to be given to mathematics teachers, necessary and sufficient guidance and aids are needed to ensure the teachers themselves are having the correct statistical thinking. This in turn will help enhancing the teachers' pedagogical knowledge in statistics education, and then able to deliver the contents fully and accurately to the students.

\section{4) The need of supporting documents and tools in Statistics Education}

From the data obtained from the interviews, as well as from the documents analysis by comparing textbook contents and Standard Curriculum and Assessment Documents (SCAD) in topic Dispersion for Ungrouped Data, textbooks existed currently are not sufficient enough to provide the necessary guidance to the teachers in teaching statistics. Zari, Dini, Rasyid and Nura have the same view of that there are loopholes on the concepts that are not throughly covered in SCAD and textbooks that are being used as the main references for the teachers. According to Zari, in Dispersion for Ungrouped Data topic, he discovered that the contents in the textbook are not aligned with the contents desired by SCAD. Not aligned here means, there are contents in SCAD that are not covered enough in the textbook. Furthermore, the standards of learning targeted by SCAD are not fully realized in the textbook.

As an example, learning standard has explained the strengths and the weaknesses of having a variety of scattering measurements to elaborate non-cumulative data. $80 \%$ of the teachers think that the examples given by the textbooks are related but limited and thus the explanations in the textbooks are too simple and not clear enough. Such as the use of graphical representations which focusing mainly on dots plotting, and limited elaboration for situation that requires interpretation and elaboration related to scattering non-cumulative data, and these are not helping teachers to further deepen their knowledge and understanding. Hence, it is important for the teachers to be provided with supporting curriculum docu- 
ments as a guidance for them to teach statistics. Deeba with a view, that;

“The teachers' concerns are the lack of supporting tools and the reliance on textbooks."

(Deeba)

All of the teachers have suggested that a guide module to be given to the teachers who are teaching statistics and the current tools are considered not sufficient enough to cater the students' and teachers' needs. Fiza, Deeba and Nura have suggested that the module creation should include elements of integrating Science, Technology, Engineering and Mathematics (STEM) in its development. According to Deeba, this element can be very helpful for the teachers and to help nurturing individuals with statistical thinking, able to face data with an added STEM values and skills in producing a generation that prioritizing on global wellness. This can help teachers to expand their students' minds towards the importance of having statistical thinking in the era of big data. According to Garfield et al. (2015), to develop learning tools in statistics by considering the experts-novices paradigm, it is not necessarily means that a student has to think like an expert, but instead it is enough for the student to have a thinking model based on the experts so that it can be used to form an idea that can help in planning and solving a certain problem. It is hoped that students can be nurtured into a current and future citizen that use statistical thinking to make a better decision (Bailey et al., 2020).

\subsection{Teachers' Views on the Use of Real-Time Data in Statistics Education for Secondary Four Students}

With the occurrence of data dumping phenomenon, hence the emergence of research on the need of developing statistical thinking in understanding big data (Ashley Steel et al., 2019; González et al., 2020; Toledo et al., 2018; Hoerl et al., 2014) so to further enhance the quality of living. Big data is an important aspect in innovation that is gaining more attention in the current age (Baig et al., 2020; Webb-Vargas et al., 2017; Storey \& Song, 2017) and has become the prime stream in most current research fields (Chen et al., 2020). In the current situation of statistics education in Malaysia, the use of real-time data is still loose especially those involving big data. This is proven based on the documents analysis on the contents of Mathematics textbook in statistical field that are being currently used in schools in Malaysia. Based on the findings from the interviews, all teachers shared the same opinion in which, the use of real-time big data should be introduced to Secondary Four students so to equip them in gacing the real-life situations that are filled with varieties of big data. However, the transition from the use of small scaled fictional data to real-time big data can be quite challenging to the teachers (Johnson, 2019), though the use of real-time data is capable in revolutionizing the use of data sets that are richer to be analysed. Currently and in the future, big data will be broadly integrated in more fields such as traffics, energy consumptions, public security, internet and communication 
(Jiang, 2015).

$100 \%$ of the teachers suggested for a module to be developed that is focusing on the development of statistical thinking by applying real-time big data considering that this situation is becoming essential to be exposed to the students. Furthermore, the limited knowledge among Mathematics teachers in data field involving big data will be the main challenge that needs to be overcome by the teachers in order to make teaching and learning in statistics is successful. This is due to the fact that, the use of big data is a new approach that hasn't been implemented before in statistics education. Deeba and Rasyid with their respective opinions;

"I believe, when it comes to big data, even the teachers are not yet capable."

(Deeba)

"It will be great if it comes in a module. Even the teachers are not knowledgeable enough with statistical thinking involving big data, which is important for the current global situation. It will be great if there is a guide for the teachers."

(Rasyid)

Eventhough $30 \%$ of the teachers have expressed their concern on the use of big data which might cause statistics education in secondary level to become more difficult, but they acknowledged the need to implement big data in statistics education so that students will be more aware and attentive on its existence and how to accurately use the data around the. Table 2 shows a summary of findings from four teachers' views on the application of real-time data in statistics education for Secondary Four (Gred 10) students.

The emergence of big data caused the existence of variety of new problems (Ridgway, 2016) and has changed our daily life (Chen et al., 2019). However, the use of big data in statistics education curriculum is a need to equip the younger generation in facing future challenges. The skill in interpreting big data has becoming more important and it needs a major role in statistical thinking in order to produce meaningful results (Webb-Vargas et al., 2017). This increasing need

Table 2. Teachers' views on the application of real-time data in statistics education

\begin{tabular}{|c|c|c|c|}
\hline Sue & Deeba & Shima & Dini \\
\hline $\begin{array}{l}\text { Big data application in the } \\
\text { development of statistical } \\
\text { thinking } \\
\text { - Too ambitious } \\
\text { - Can be applied but more } \\
\text { on introductory level as } \\
\text { an early exposure for } \\
\text { future use }\end{array}$ & $\begin{array}{l}\text { Big data application in the } \\
\text { development of statistical thinking } \\
\text { - Very good } \\
\text { - Students will enjoy more in } \\
\text { solving statistical problems } \\
\text { - Students get to apply the data } \\
\text { surrounding them in solving } \\
\text { problems with statistical skills and } \\
\text { the exposure on real-time big data }\end{array}$ & $\begin{array}{l}\text { Big data application in the } \\
\text { development of statistical thinking } \\
\text { - Application real-time big data that } \\
\text { are relevant to real life } \\
\text { - Integrated it in statistics education } \\
\text { curriculum } \\
\text { - Help in developing statistical } \\
\text { thinking. Students able to see the } \\
\text { usage. } \\
\text { - Preparing students in facing } \\
\text { challenges in the future }\end{array}$ & $\begin{array}{l}\text { Big data application in the } \\
\text { development of statistical thinking } \\
\text { - Very important since the world is } \\
\text { having big data dumping } \\
\text { - The real-time big data application } \\
\text { should come together with the } \\
\text { exposure on the relevant } \\
\text { computer softwares }\end{array}$ \\
\hline
\end{tabular}


should be encouraging in changing statistics curriculum so that is capable in nurturing a current generation that are not only aware in statistics, but also data minded.

\section{Conclusion}

Changes in statistics education curriculum are an appropriate step to be taken so to fulfill the need of current generation of the era of big data. However, in making changes, statistics curriculum developers have to take these few factors into considerations, which are focusing on statistical thinking development, application of real-time data and the use of big data, providing sufficient guidance for the teachers and improving the curriculum contents arrangements following priority sequencing from statistics to calculations so that statistics is not seen as just a calculation skill.

Even though there are concerns among the teachers on the increasing difficulties in statistics education for Secondary Four students if it involves the use of real-time data, however, some positive views from the teachers clearly show their acknowledgment on the importance of this matter. Hence, it is hoped by the teachers that the implementation of this change in statistics education should come together with the relevant guidance aligned to the current situation. This is to allow the teachers to be able to deliver the changes effectively and able to apply the necessary pedagogical approach according to the needs of the students. The findings have given a clear implication on the elements that need to be considered in the development of the statistics education curriculum, as well as the challenges faced by the teachers in teaching statistics. A further suggestion is to have a further research and study regarding the development of teaching modules that are suited with the need of statistics education in the era of big data. Some of the focuses that need to be included in the developments of the modules are focused on statistical thinking process in learning activities, the use of realtime big data supported by the use of relevant computer software and integrating STEM education. Continuous efforts in transforming statistics education curriculum can potentially enhance rational thinking as well as produce useful ideas which involve statistics application in daily life so to ensure the global wellness and its harmony to continue to flourish.

\section{Acknowledgements}

This research was partially supported by the Grant STEM and Minda: GG-2021-001.

\section{Conflicts of Interest}

The authors declare no conflicts of interest regarding the publication of this paper.

\section{References}

Adam, M. B. (2020). Career Breaks and Challenges a Statistician. Science Magazine. 
https://www.majalahsains.com/susur-galur-kerjaya-dan-cabaran-seorang-ahli-statistik/

Alston-Knox, C. L., Strickland, C. M., Gazos, T., \& Lee, M. K. (2019). Teaching and Learning in Statistics: Harnessing the Power of Modern Statistical Software to Improve Students' Statistical Reasoning and Thinking. 5th International Conference on Higher Education Advances, València, 25-28 June 2019, 1171-1178.

https://doi.org/10.4995/HEAD19.2019.9239

Ardiansyah, A. S., Novita, N. A., Zhintya, H., \& Kurnianto, D. (2020). Realistic-Science, Technology, Engineering, and Mathematics Assisted by Google Classroom as a Learning Innovation in the New Normal Era to Improve Statistical Thinking Skill. Journal of Physics: Conference Series, 1918, Article ID: 042084. https://doi.org/10.1088/1742-6596/1918/4/042084

Ashley Steel, E., Liermann, M., \& Guttorp, P. (2019). Beyond Calculation: A Course in Statistical Thinking. The American Statistician, 73, 392-401.

https://doi.org/10.1080/00031305.2018.1505657

Australian Curriculum (2015). Australian Curriculum, Assessment and Reporting Authority. https://www.australiancurriculum.com.au

Baig, M. I., Shuib, L., \& Yadegaridehkordi, E. (2020). Big Data in Education: A State of the Art, Limitations and Future Research Directions. International Journal of Education Technology in Higher Education, 17, Article No. 44. https://doi.org/10.14221/ajte.2020v45n1.1

Bailey, J., Cowie, B., \& Cooper, B. (2020). “Maths Outside of Maths”: Pre-Service Teachers' Awareness of Mathematical and Statistical Thinking Across Teachers' Professional Work. Australian Journal of Teacher Education, 45, 1-18.

Chance, B. L. (2017). Components of Statistical Thinking and Implications for Instruction and Assessment. Journal of Statistic Education, 10, 1-14.

Chen, M., Zhu, X. S., \& Jiang, Q. (2019). Challenges to Traditional Statistics in the Age of Big Data. 7th International Conference on Arts, Management, Education and Innovation, London, 30 March-1 April 2019, 1073-1076.

Chen, N.-S., Yin, C., Isalas, P., \& Psotka, J. (2020). Educational Big Data: Extracting Meaning from Data for Smart Education. Interactive Learning Environments, 28, 142-147. https://doi.org/10.1080/10494820.2019.1635395

Cox, D. R., \& Efron, B. (2017). Statistical Thinking for 21st Century Scientists. Science Advances, 3, Article ID: e1700768. http://advances.sciencemag.org/ https://doi.org/10.1126/sciadv.1700768

Cummiskey, K., Adams, B., Pleuss, J., Turner, D., Clark, N., \& Watts, K. (2020). Causal Inference in Introductory Statistics Courses. Journal of Statistics Education, 28, 2-8. https://doi.org/10.1080/10691898.2020.1713936

Doluzengin, B., \& Kazak, S. (2019). How Realistic Mathematics Education Approach Influences 6th Grade Students' Statistical Thinking. 11th Congress of the European Society for Research in Mathematics Education, Utrecht, February 2019, hal-02411583.

English, L. D., \& Watson, J. M. (2015). Exploring Variation in Measurement as a Foundation for Statistical Thinking in the Elementary School. International Journal of STEM Education, 2, Article No. 3. https://doi.org/10.1186/s40594-015-0016-X

Garfield, J., Le, L., Zieffler, A., \& Ben-Zvi, D. (2015). Developing Students' Reasoning about Samples and Sampling Variability as a Path to Expert Statistical Thinking. Educational Studies in Mathematics, 88, 327-342.

https://doi.org/10.1007/s10649-014-9541-7

González, O., Isoda, M., \& Araya, R. (2020). Statistical Thinking for the Era of Big Data 
and Artificial Intelligence: Toward Understanding Sustainability Trends and Issues for the Future Society. In P. Arnold (Ed.), New Skills in the Changing World of Statistics Education: Proceedings of the Roundtable Conference of the International Association for Statistical Education (pp. 1-5). International Association for Statistical Education, Voorborg.

https://iase-web.org/documents/papers/rt2020/IASE2020\%20Roundtable\%2026 GON ZLEZ.pdf?1610923749

Gu, Y. (2021). Eliciting and Deciphering Mathematics Teachers' Knowledge in Statistical Thinking, Statistical Teaching, and Statistical Technology. Unpublished Doctoral Dissertation, University of Columbia.

Hoerl, R. W., Snee, R. D., \& De Veaux, R. D. (2014). Applying Statistical Thinking to 'Big Data' Problems. WIREs Computational Statistics, 6, 222-232.

https://doi.org/10.1002/wics.1306

Jiang, X. (2015). Reflection on Quality Assurance System of Higher Vocational Education under Big Data Era. SHS Web of Conferences, 14, Article ID: 01009.

https://doi.org/10.1051/shsconf/20151401009

Johnson, T. A. (2019). The Search for Evidence of Statistical Thinking: How Secondary Education Teachers' Reason with Non-Traditional Data. Unpublished Doctoral Dissertation, University of California.

Le, L. (2017). Assesing the Development to Statistical Thinking: An Exploratory Study. Unpublished Doctoral Dissertation, University of Minnessota.

Lee, S. (2015). The First Step to Good Clinical Research: Statistical Thinking. Korean Journal of Anesthesiology, 68, 99-100. https://doi.org/10.4097/kjae.2015.68.2.99

Lukman, \& Wahyudin (2020). Statistical Literacy of Undergraduate Students in Indonesia: Survey Studies. Journal of Physics: Conference Series, 1521, Article ID: 032050. https://doi.org/10.1088/1742-6596/1521/3/032050

Maheran, U. H., \& Abdullah, A. H. (2017). High Order Thinking Skills (HOTS): Statistical Thinking Level for Secondary Four Students in Ledang District. UTM Press.

Marriott, N. (2014). The Future of Statistical Thinking. Significance, 11, 78-80. https://doi.org/10.1111/j.1740-9713.2014.00787.x

Masjudin, M., Muzaki, A., Abidin, Z., \& Ariyanti, I. A. P. (2020). Analysis of Students' Statistical Thinking Ability in Understanding the Statistical Data. Journal of Physics: Conference Series, 1521, Article ID: 032063. https://doi.org/10.1088/1742-6596/1521/3/032063

Meylasari, N. D., Sujadi, I., \& Subanti, S. (2021). The Profile of 8th Graders' Level of Statistical Thinking: A Case of Analyzing and Interpreting Data. Journal of Physics: Conference Series: Earth and Environmental Science, 1796, Article ID: 012052. https://doi.org/10.1088/1742-6596/1796/1/012052

Ministry of Education Malaysia (2018). Secondary School Standard Curriculum: Mathematics: Standard Curriculum and Assessment Documents Form 4 and Form 5. Curriculum Development Division.

Ministry of Education Malaysia (2020). TIMSS National Report: Trends in International Mathematics and Science Study. Education Planning and Research Division.

Ministry of Education Singapore (2019). Mathematics Syllabus Secondary One to Four. Express Course Normal (Academic) Course. Curriculum Planning and Development Division.

Moore, D. S. (1988). Should Mathematicians Teach Statistics? College Mathematics Journal, 19, 3-7. https://doi.org/10.2307/2686686 
Rahayu, N. A., \& Wijaya, A. (2018). Hypothetical Learning Trajectory: A Case of Statistical Thinking. Journal of Physics: Conference Series, 1097, Article ID: 012109. https://doi.org/10.1088/1742-6596/1097/1/012109

Ramadhani, R., Sri Bina, N. S., Narpila, S. D., \& Rusmini (2018). The Development of Student Worksheet and Test Instrument for Statistical Thinking Skill Based on Local Culture and Accordance with Curriculum 2013 in Indonesia: Design Research Stage. Advances in Social Science, Education and Humanities Research, 208, 153-157.

Ridgway, J. (2016). Implications of the Data Revolution for Statistics Education. International Statistical Review, 84, 528-549. https://doi.org/10.1111/insr.12110

Storey, V. C., \& Song, I.-Y. (2017). Big Data Technologies and Management: What Conceptual Modeling Can Do. Data \& Knowledge Engineering, 108, 50-67. https://doi.org/10.1016/j.datak.2017.01.001

Taylor-Sakyi, K. (2016). Big Data: Understanding Big Data. Aston University. https://www.researchgate.net/publication/291229189

Toledo, J. C., Lizarelli, F. L., Santos, A. B., \& Ishizaka, A. (2018). Statistical Thinking in Quality Improvement: Use, Difficulties and Benefits of Its Implantation in Industries of the Brazilian State of São Paulo. Production, 28, Article ID: e20180062.

https://doi.org/10.1590/0103-6513.20180062

Wang, L., Liu, Q., Du, X., \& Liu, J. (2017). Chinese Mathematics Curriculum Reform in the 21st Century: A Review. Eurasia Journal of Mathematics, Science and Technology Education, 13, 5311-5326. https://doi.org/10.12973/eurasia.2017.01005a

Webb-Vargas, Y., Chen, S., Fisher, A., Mejia, A., Xu, Y., Crainiceanu, C., Caffo, B., \& Lindquist, M. A. (2017). Big Data and Neuroimaging. Statistics in Biosciences, 9, 543-558. https://doi.org/10.1007/s12561-017-9195-y

Zhang, Q., \& Stephens, M. (2016). Profiling Teacher Capacity in Statistical Thinking of National Curriculum Reform: A Comparative Study between Australia and China. Eurasia Journal of Mathematics, Science and Technology Education, 12, 733-746. https://doi.org/10.12973/eurasia.2016.1225a 